\title{
Luster e Lena - Trapos, trocados e confinamentos
}

Fecha de recepción: 30/5/2020. Fecha de aceptación: 30/10/2020.

\begin{abstract}
Resumo
Pretendemos aproximar dois romances de Faulkner, O Som e a Fúria e Luz em Agosto, para alcançar uma compreensão do que entendemos como força estruturante nas obras do autor: o confinamento no espaço e no tempo. Para isso, será necessário estudar como as jornadas e tentativas de fugas dos personagens são frustradas ou bem sucedidas. Serão tomadas como base aqui dois capítulos dos romances onde percebemos que o confinamento e possível liberdade se dá através da linguagem e sintaxe usada pelos narradores.
\end{abstract}

Palavras-chaves: Faulkner; literatura estadunidense; confinamento.

\section{Sobre O Som e a Fúria e Luz em Agosto}

\begin{abstract}
In this paper, it is intended to approximate two Faulkner's novels, The Sound and the Fury and Light in August, to reach a higher comprehension of what is understood by us as structuring force in the author's work: time and space confinement. For that to be achieved, it is necessary to study how the characters' journeys and escape trials are frustrated or successful. To illustrate that point, we use two chapters in which the confinement and possible freedom are noticed through the language and syntax used by their narrators.

Keywords: Faulkner; United States literature; confinement.
\end{abstract}


Publicado em 1932, o romance Luz em Agosto de William Faulkner se encontra em um período curioso da produção do autor. Após a publicação, em 1929, de $O$ Som e a Fúria, o autor intensificou as experimentações modernistas que teve que abandonar após o primeiro capítulo do romance por questões de necessidade estética da obra. O resultado desse experimento foi o romance Enquanto Agonizo de 1930. No ano seguinte, o autor publicou Sanctuary, descrito pelo próprio Faulkner como um potboiler, isto é, um romance escrito por motivações meramente financeiras. Embora isso tenha ocorrido (foi com esse romance que a reputação do autor foi cimentada), muitos críticos hoje discutem se essa foi realmente a intenção do autor, já que a obra apresenta méritos.

Após esse período surgiu Luz em Agosto. Não tão experimental sem deixar de lado inovações modernistas, o romance se apresenta de modo mais seguro no que pretende alcançar. Enquanto podemos debater qual o fim estético de Enquanto Agonizo, se a técnica está em vantagem em relação à forma ou se ela é um meio de transformação do conteúdo específico do momento em forma adequada, no romance de 1932 podemos notar que cada passo da obra tem um objetivo específico: uma configuração do Sul dos Estados Unidos e o projeto de nação em vigor que teima em mostrar sua cara através do passado.

Como leitores de Faulkner, já temos visto desde O Som e a Fúria, a criação de um território fictício, Jefferson no condado de Yoknapatawpha, que não busca criar um passado imaginário, aos moldes do romantismo brasileiro. Muito pelo contrário, pela ficção de Faulkner, o projeto de país estadunidense sai do papel, e através da mimese permite uma interpretação da história que se vê livre dos mitos da formação da nação. O Som e a Fúria fez isso através da família Compson, oligarquia nos períodos finais da decadência financeira que ilustra a movimentação histórica da região sul. ${ }^{1}$ Luz em Agosto dá continuidade a esse processo representando personagens de classe popular.

Tais obras de Faulkner representam a formação, ou a pré-configuração, de um ethos particular. Sabemos que novos ethos são seguidos por novas manifestações de formas artísticas, como a hegemonização das formas do romance ou da novela em certos períodos históricos.

Trabalhamos a manifestação da forma artística como a transformação orgânica de um dado conteúdo. Em O Som e a Fúria, as novidades do modernismo e o projeto de prosa de Faulkner apresentam tanto harmonias como conflitos.

É verdade que quando nos deparamos com o romance somos tomados por uma confusão. A narração tem início específico, 7 de abril de 1928. Porém, não somos apresentados a esse mundo aos poucos. A narrativa começa in medias res. Imediatamente, o mundo de Benjamin aparece pelo único meio que pode o fazer, pela linguagem. Como é um personagem com deficiência, percebemos em sua

1 Oklopcic (2014) escreve sobre os ciclos de passagem de tempo e a representação que a família Snope faz disso em relação com o Sul dos EUA. 
linguagem uma ausência de componente humano. Isto é dizer que ela nos é apresentado sem aprofundar na questão humana que é representada pela linguagem. Sua sintaxe é imediata e não busca ir além das frases ali.

Through the fence, between the curling flower spaces, I could see them hitting. They were coming toward where the flag was and I went along the fence. Luster was hunting in the grass by the flower trees. They took the flag out, and they were hitting. Then they put the flag back and they went to the table, and he hit and the other hit. Then they went on, and I went along the fence. Luster came away from the flower tree and we went along the fence and they stopped and we stopped and I looked through the fence while Luster was hunting in the grass (Faulkner, 1990, p. 3).

Chama a atenção a construção da primeira sentença. Começa com uma locução prepositiva ("Through the fence") e é seguida por outra ("between the curling flower spaces") para só então, finalmente, chegarmos a oração principal (“I could see them hitting”). Após a primeira sentença, a ordem toma pelo restante do capítulo a ordem comum de sujeito-verbo-objeto.

Então, qual a importância da sintaxe da primeira sentença? O valor da imagem é significativo. "Através da grade" nos remete imediatamente à ideia de prisão. 0 confinamento de Benjamin estará presente pelo restante do texto. Não apenas em sua condição mental, mas também fisicamente. O que ficará claro mais adiante, é que o confinamento não se restringe ao membro mais vulnerável da família Compson, mas a todos eles, seus servos e também a sociedade ali representada por mediação dessa família.

“Entre os espaços encaracolados das flores” é a locução prepositiva que interrompe a ligação entre a prisão ("através da grade") e a ação ("eu podia vê-los batendo"). Essa interrupção é melancólica, por motivos que ficarão claros posteriormente, e contrasta a prisão da grade e a beleza das flores. Ao mesmo tempo, a grade e as flores ocupam o mesmo espaço e ambos marcam a distância entre Benjamin e o mundo de fora, pelo qual anseia.

Após essas locuções, temos a ação finalmente. "Eu podia vê-los batendo" é uma oração confusa. Principalmente porque é a primeira. Não sabemos no que estão batendo. Logo adiante na narrativa, perceberemos que estão jogando golfe. Isso aparece aos poucos ("onde a bandeira estava", "retiraram a bandeira, e estavam batendo" "colocaram a bandeira de volta" "ele bateu e o outro bateu"), mas gradualmente a imagem se forma para o leitor. Da mesma maneira que o resto também alcança unidade final.

No capítulo narrado por Benjamin, os tempos verbais são dois: past simple e past continuous. ${ }^{2}$ Assim, o confinamento que nos deparamos já demonstra

2 São tempos verbais que se assemelham à ideia do pretérito perfeito simples, sendo que o foco do primeiro está na ação e o segundo no tempo da ação. Não cabe aqui nos prolongarmos nas diferenças entre os tempos verbais do inglês e do português. Por hora, é interessante notar a ausência de um tempo como o pretérito imperfeito do inglês, que para ser expressado deve usar outras formas que não as das flexões verbais. 
uma dependência clara com o passado. Temos uma constante mudança de perspectivas dentro do passado. E nossa caminhada por ele é muito confuso. Passo a passo, o passado é desenredado pela narrativa. Afirmo, logo, que o enredo de $O$ som e a fúria é precisamente um de volta ao passado para tentar elucidar o presente.

Os personagens não são apresentados, eles recebem nomes e aos poucos se formam. Enquanto os personagens vão aparecendo, o mundo do romance se constrói:

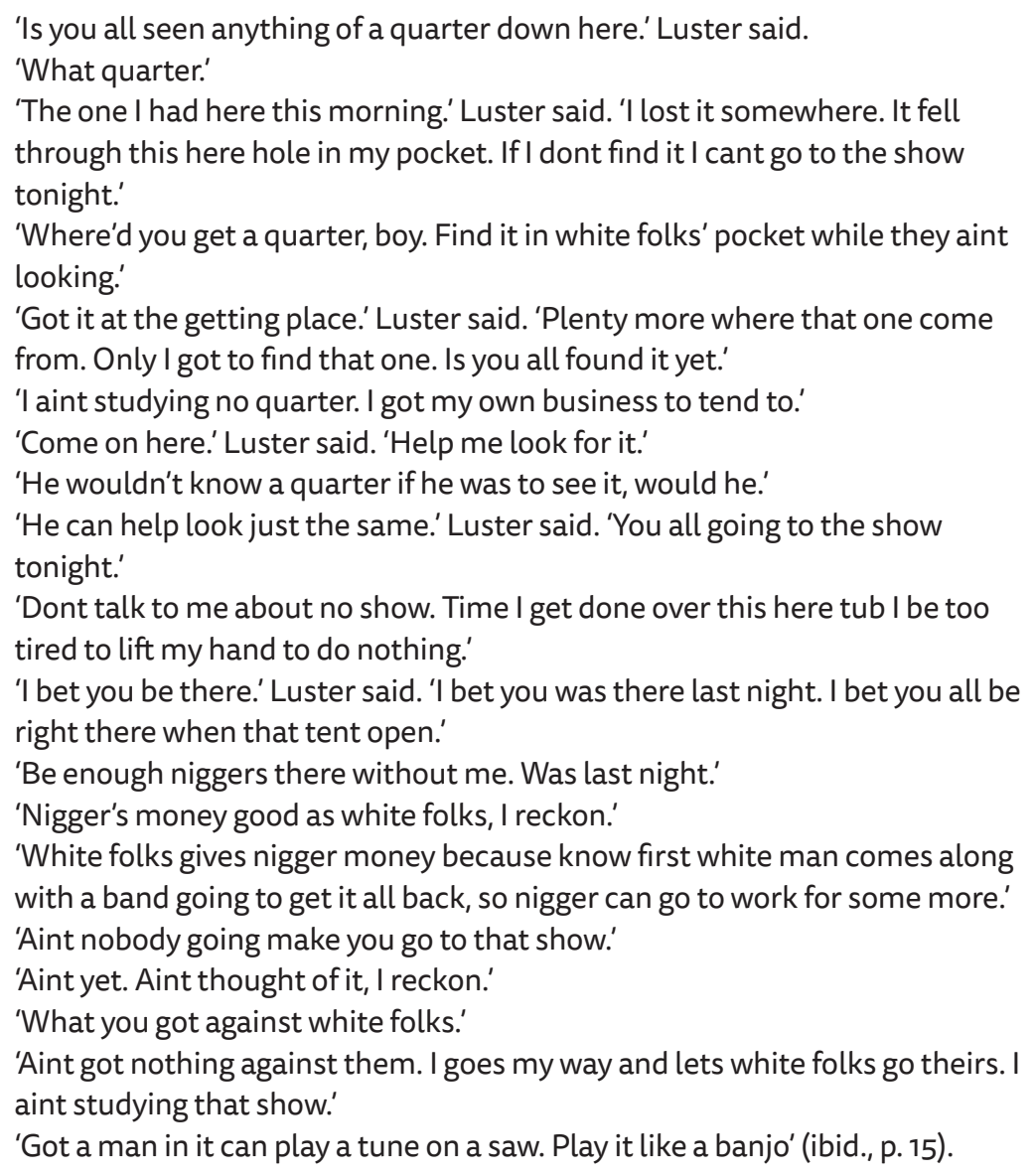

A passagem acima é construída com muita habilidade. A linguagem dos personagens é a primeira responsável por apresentá-los. São dois negros. Luster, um menino de 14 anos responsável por cuidar de Benjamin de 33 anos, conversa com Roskus, seu avô. $\mathrm{O}$ nome do último só nos será apresentado aos poucos. Podemos identificá-lo pelo comentário que faz ("Não me fale de show. Quando acabar com essa banheira estarei muito cansado para levantar a mão para fazer nada"). Descobriremos mais tarde que Roskus, servo dos Compsons, sofre de grave reumatismo.

A sintaxe não convencional, por mais que seja imediatamente um modo naturalista de retratar certos grupos da sociedade, consegue introduzir ao leitor o que 
Benjamin não sabe. ${ }^{3}$ Percebemos que a narrativa de Benjamin não consegue distinguir nem as afirmações das interrogações, como evidenciado pela ausência de pontos de interrogação. Como previamente dito, a sintaxe de Benjamin Compson é incapaz de nos levar a significação humana por trás dos símbolos da linguagem. Mas, então, como é possível existir humanidade na narrativa deste capítulo?

Primeiro devo afirmar que há humanidade, há significação histórica. Voltemos à citação prévia. Luster encontra por acidente uma moeda e também a perde por acaso. Aqui o acaso não permanece no terreno do arbitrário. Há um grupo de artistas que estão passando pela cidade e Luster quer muito assistir o show. A moeda toma então significado. Ela é a possibilidade de Luster ter um pouco de entretenimento. $O$ modo que ele encontra a moeda e também como a perde deixa de ser apenas por acaso porque a narrativa preenche as lacunas e cria paulatinamente mediações entre a casualidade e a causalidade.

A família de Luster, representados no topo por Roskus e sua esposa Dilsey (a personagem comum a todas as narrativas diferentes no romance), é composta por ex-escravos. A abolição da escravidão não alterou o destino deles, que continuaram servos dos Compsons. De tal modo que o único modo que seria possível para Luster encontrar uma moeda foi como ele conseguiu: por acaso enquanto cuidava de Benjamin e o levava para um passeio pela propriedade. Luster não gastou a moeda, ele a perdeu também enquanto cuidava de Benjamin em seus passeios. A moeda caiu porque a roupa de Luster estava em péssima condições (é um servo) e com buracos no bolso.

Essa ocorrência da sorte permite todo o diálogo que vimos acima. Nele é possível enxergar um pouco do mundo do romance. Mais precisamente, a situação dos servos. Ambos, avô e neto, estão trabalhando para seus senhores. Fica claro que o trabalho dos dois toma a vida cotidiana deles quase que por completo. E não há ligação nenhuma entre o produto de seus trabalhos e suas personalidades. 0 avô limpa uma banheira que não tem importância nenhuma para ele ao mesmo tempo que fere seu corpo com isso. 0 neto, ainda um jovem de 14 anos, tem toda sua infância consumida enquanto cuida de um adulto que tem sua infância tardia mantida às custas dos serviços do garoto.

Então, aparece na cidade um grupo de artistas. A chegada do grupo também pode ser uma causalidade, já que poderiam passar na cidade em outro momento ou nem ir lá. Veremos mais adiante no romance que o show tomará importância central no tempo presente do romance. Por hora, nos é suficiente perceber como que a chegada do show desencadeia o diálogo entre Roskus e Luster.

A possibilidade de ir ao show nem existe para Roskus, pois não há noção de entretenimento para ele. Ao fim do trabalho (lavar a banheira) seu corpo estará demasiadamente dolorido. Deverá descansar para poder retomar a rotina no dia

3 Benjamin não pode apresentar a condição de Luster e Roskus, assim como não consegue apresentar a si mesmo. 
seguinte. Mesmo assim, a conversa sobre o show é capaz de trazer a discussão de raça: "Dinheiro de negro é tão bom quanto o de branco"; "brancos dão dinheiro para negros porque sabem que o primeiro branco que vier com uma banda vai ganhar tudo de volta, então o negro pode voltar para mais", etc.

Essa conversa só pôde ocorrer por causa da moeda e por causa da presença de Benjamin. Foi dito acima que a moeda só pôde chegar a Luster porque esse cuidava de Benjamin quando a encontrou. A conversa e seu teor só pode ocorrer também por causa de Benjamin. Primeiro porque as coisas não poderiam ser ditas (a relação dos servos e o trabalho, a relação entre brancos e negros, etc.) se ao invés de Benjamin tivéssemos outro membro da família Compson ou outro personagem branco. Segundo, sem Benjamin, avô e neto não se encontrariam nesse mesmo momento, pois ambos estariam trabalhando em locais separados. A casualidade do local de passeio de Benjamin permite que Luster e Roskus se encontrem enquanto trabalham. De fato, sem a presença do "ser anormal ou idiota", não teríamos o primeiro capítulo inteiro.

O material narrativo da decadência da família Compson e a sua capacidade representativa de uma nação fez com que fosse esteticamente necessário o ponto de vista mais totalizante do que a narrativa de Benjamin permitia.

Luz em Agosto dá continuidade a esse projeto. Através da chegada de alguns personagens à cidade de Jefferson (criada em $O$ Som e a Fúria), a narrativa pula de presente para passado constantemente. Um ambicioso projeto, devemos nos lembrar que foi publicado em 1932, o romance lida com relações de classe, raça e gênero no coração do conservadorismo estadunidense.

A convoluta linha do tempo do romance só pode ser compreendida através das resoluções violentas do enredo. Em verdadeira moda realista, o passado só pode explicar o presente porque o último explica o primeiro. Isso por si só já é uma partida significativa da ideologia modernista da fragmentação. Esse dilaceramento da chamada "distância épica" entre o passado e presente não é outra coisa senão épico por si mesmo. Pois é através dessa conexão histórica que se busca o projeto de formação de nação que se configura através de um novo ethos.

Um novo epos para um novo ethos. Enquanto essa proposição ainda não está aqui concretizada, é em Luz em Agosto que as peças começam a mostrar o delineamento de um complexo quebra-cabeças. Esse enigma violento que é a construção da nação começou a ser montado em $O$ Som e a Fúria. Lá, as peças eram a oligarquia decadente e como seu poder financeiro foi construído nas costas, figurativa e literal, da escravidão. 0 romance de 1929 se estruturava nas relações das pessoas dessas classes e como relações de classe e raça se mostram intimamente associadas.

Como já mencionado acima, temos no romance de 1932 pessoas das classes médias e baixas. Isso permite uma visão distinta da apresentada em $O$ Som e a Fúria e que se aproxima de Enquanto Agonizo. Neste último, a família protagonista 
é uma de pequenos fazendeiros que fazem uma peregrinação pelo condado fictício de Yoknapatawpha até a cidade de Jefferson (sempre ela) para enterrar a matriarca da família, de acordo com seu desejo.

Além das experimentações técnicas do romance, Enquanto Agonizo nos permite uma configuração irônica que, graças a isso, pode ir além dos exercícios de vanguarda. Os aparatos anti-realistas da narrativa da obra, como defuntos e deficientes mentais narrando capítulos, são artífices da configuração de uma realidade singular que nos é apresentada conforme conhecemos os membros dessa família.

Já mencionamos pontos de interesse do romance, que recebe de nosso estudo um interesse apenas periférico, pois poderíamos extrapolar os limites de nosso escopo. Para esse nosso capítulo, nos basta a ironia do movimento da família Bundren até Jefferson e como a saga ilustra a estagnação do Sul post-bellum.

Enquanto o romance de 1930 é permeado por um pessimismo, já que o fatalismo da saga da família Bundren já é anunciada no título, há em Luz em Agosto a possibilidade de novas vidas pela locomoção. Embora o autor tenha rejeitado essa interpretação do título (cf. Rupersburg, 1994), é difícil fechar os olhos para a aparente alusão que o nome do romance faz ao nascimento da criança de Lena Grove.

Lena já abre o romance com sua jornada desde o Alabama até a cidade de Jefferson, no Mississipi, a qual ela faz a pé, com eventuais caronas em carroças de estranhos. Nos primeiros parágrafos do romance já somos apresentados a dualidade movimento-estagnação. $O$ que se evidencia com a passagem do romance é que a movimentação de Lena representa também a mudança de sua fortuna. Essa peripécia de Lena, no sentido clássico de suas origens gregas, a mudança de fortuna do herói, adquire proporções maiores logo nas primeiras páginas. O destino de Lena sempre foi decidido por outros, ou seus pais, seu irmão ou o amante que tirou proveito dela. Enquanto Lena observa a carroça que se aproxima, ela já havia tomado a decisão de tomar sua fortuna pelas rédeas e o leitor vai se inteirar desse fato na medida que o romance progride carregado pelos pés descalços de Lena.

Sitting beside the road, watching the wagon mount the hill toward her, Lena thinks, 'I have come from Alabama: a fur piece. All the way from Alabama a-walking. A fur piece.' Thinking although I have not been quite a month on the road I am already in Mississippi, further from home than I have ever been before. I am now further from Doane's Mill than I have been since I was twelve years old (Faulkner, 2005, p. 5)

O primeiro parágrafo do romance nos apresenta Lena maravilhada com sua façanha, que é acentuada por sua humildade. Esse estilo de prosa será o tom da narrativa que se ocupa de Lena. É uma prosa lírica, carregada de aliterações ("I have come from Alabama: a fur piece. All the way from Alabama a-walking. A fur piece") que simboliza em seu ritmo a distância e o passado que Lena carrega em seus passos. Cada oração da narrativa nos transmite os sons e o suor da jornada 
de nossa personagem. Sua lírica também combina passado e presente e mira no futuro, como exemplificado pelo uso do tempo verbal present perfect ("I have come from Alabama"; "I have not been quite a month on the road"; "further from home than I have ever been before": "further from Doane's Mill than I have been since I was twelve years old.")

O narrador retorna e nos transporta para outro tempo verbal:

She had never even been to Doane's Mill until after her father and mother died, though six or eight times a year she went to town on Saturday, in the wagon, in a mail-order dress and her bare feet flat in the wagon bed and her shoes wrapped in a piece of paper beside her on the seat. She would put on the shoes just before the wagon reached town. After she got to be a big girl she would ask her father to stop the wagon at the edge of town and she would get down and walk. She would not tell her father why she wanted to walk in instead of riding. He thought that it was because of the smooth streets, the sidewalks. But it was because she believed that the people who saw her and whom she passed on foot would believe that she lived in the town too (ibid., p. 5).

Com a transição para o past perfect, o tempo de uso similar do pretérito mais-queperfeito, ele já situa o leitor em dois passados distintos: quando seus pais eram vivos e após a morte deles. A vida com os pais, representado através de rotinas passadas (com tempos verbais semelhantes ao pretérito imperfeito) nos transmite uma certa tranquilidade que é temperada por uma inocência otimista e a promessa que a cidade oferece em relação ao campo. A pequena Lena já fazia um julgamento de valor em relação às pessoas da cidade: ela queria chegar a pé nas cidades, ao invés da carroça da família, porque queria que as pessoas da cidade a enxergassem como uma deles.

Duas coisas são importantes da passagem citada. A primeira é que a razão de Lena querer chegar a pé na cidade nem passa na cabeça do pai. Para o pai, as diferenças da vida na cidade e no campo não produzem um efeito qualitativo sobre quem alguém é. A cidade se apresenta nesse pequeno tempo que temos com o pai de Lena (seu pensamento transmitido quase que sem querer pelo narrador) como uma extensão de sua vida no campo.

O outro interesse é as diferenças entre as situações do passado e a atual (primeiro parágrafo). Quando criança, a pequena Lena queria chegar a pé para passar uma imagem de quem ela gostaria de ser. No presente, sua jornada a pé não parte de uma vontade, mas de uma consequência. Não que sua jornada não tenha início por uma decisão sua, que se apresentará uma decisão de força de carácter. Mas seus passos descalços não são agora um quero ser, mas um sou.

Outro parágrafo, outro tempo:

When she was twelve years old her father and mother died in the same summer, in a log house of three rooms and a hall, without screens, in a room lighted by a bug-swirled kerosene lamp, the naked floor worn smooth as old silver by naked 
feet. She was the youngest living child. Her mother died first. She said, 'Take care of paw." Lena did so. Then one day her father said, "You go to Doane's Mill with McKinley. You get ready to go, be ready when he comes." Then he died. McKinley, the brother, arrived in a wagon. They buried the father in a grove behind a country church one afternoon, with a pine headstone. The next morning she departed forever, though it is possible that she did not know this at the time, in the wagon with McKinley, for Doane's Mill. The wagon was borrowed and the brother had promised to return it by nightfall (Faulkner, 2005, p. 5)

Este trecho representa a transição dos passados de Lena. Acaba a infância com a morte dos pais e começa o período semelhante à servidão. 0 trecho une tempo e espaço com o passar dos pais: "When she was twelve years old her father and mother died in the same summer" são duas orações (a primeira uma oração subordinada adverbial de tempo) que sem serem separadas por vírgulas as colocam numa mesma ação. Essa é seguida por uma oração subordinada adverbial de lugar, "in a room lighted by a bug-swirled kerosene lamp", que vai muito além de situar a ação da oração principal. O uso das duas orações subordinadas, uma de tempo e a outra de lugar, criam essa sensação indissociável de espaço e tempo. A distância de Lena agora é marcada em duas frontes.

Curioso, então, que a sentença continue após a vírgula com uma oração na voz passiva, "the naked floor worn smooth as old silver by naked feet" "que já não tem mais ligações com a morte dos pais por via da sentença, mas pela nossa noção de espaço e tempo construída pela mesma. De fato, além da nossa percepção, a oração se liga com o que vem antes por uma metonímia, uma metalepse, para ser mais preciso, que é o emprego de "the naked floor" para fazer alusão a "in a room lighted by a bug-swirled kerosene lamp". ${ }^{5}$

Essa oração faz ligação a outras características da vida de Lena e aos seus fardos. "Naked floor" e "naked feet" aparecem mais uma vez sinalizando o lirismo da prosa de Faulkner. Os pés descalços ("naked feet”) já nos são familiares, já que ela caminha pelas estradas descalça para não gastar o sapato. Isso representa a situação econômica de Lena sem que o autor precise descrevê-la. A casa e os pés de Lena, ambos representantes reais da classe dela, se unem numa ironia que é "naked floor" (chão sem piso): os pés são descalços e o chão sem piso. 0 encontro constante dos dois amaciam e dão polimento ao chão, desgastando os pés, como se eles fossem peças antigas de prata ("old silver"). O polimento de prata é um exercício de esmero e capricho pelo valor implícito dela, numa subversão do valor qualitativo do objeto pela quantificação humana do dinheiro. Desgasta-se o corpo, pois o objeto (tanto os sapatos, como o piso ausente e a ironia da prata) diz mais sobre o valor da vida de Lena do que seu corpo.

4 É uma passagem muito complicada de ser traduzida, portanto não empreendemos em tal tarefa ingrata. Podemos explicar a oração dizendo que o chão sem piso ("naked floor") foi polido, amaciado como prata antiga por pés descalços ("naked feet").

5 Tal oração subordinada também brinca com a noção de estado (se interpretarmos "lighted" como adjetivo "iluminado") e ação passiva (se lermos como "iluminado por uma lâmpada de querosene rodeada por insetos"). A segunda interpretação não deve ser tomada levando em conta a tradução para o português, pois "lâmpada de querosene rodeada por insetos" aparece como adjetivo composto no original ("bug-swirled kerosene lamp"). 
O narrador diz sem precisar ser direto. Ele fala sem enunciar, num jogo pervertido de ironia e metonímia. As partes simbolizam o todo. Os pés são o corpo, que é Lena e sua situação. Lena é única, é ela mesma. Porém, não simboliza ela também outras Lenas que carregam suas dores e fardos também em seus corpos? E a situação social de Lena, enquanto que transformando em particularidade a situação feminina, pode dar representatividade artística à vida daquele lugar, àquele projeto de nação tão envolto em mitos fundadores que precisam passar em cima dos não-hegemônicos (mulheres, índios, negros e, em menor escala, os brancos pobres).

É o que propõe Luz em Agosto. Numa peripécia carnavalesca ${ }^{6}$ das convenções literárias, ${ }^{7}$ o romance faz paródia dos seres elevados das epopéias heróicas e nos apresenta o quarto dos fundos da projeção mítica da formação da nação. Conheceremos o sistema pela via periférica, com seus personagens periféricos e marginalizados. Mais adiante veremos como a paródia aqui vai além, subvertendo também o gótico sulista.

E é no silêncio do que não é dito que essas imagens ganham complexidade. Tomemos a sentença "She was the youngest living child". O superlativo "the youngest" (a mais nova) é modificado pelo adjetivo "living" (viva). Ou seja, a mais nova das crianças vivas. E é isso. Não há menções às mortes dos outros filhos, nem quantos foram, mas eles existem. $O$ ausente se faz presente e somando ao que já sabemos (lembremos que ainda estamos no terceiro parágrafo do romance), a situação de classe de Lena ganha dimensões mais severas. Até onde a classe se apresentava pelos pés, pelo campo e pelo chão, ela agora grita (em silêncio, é verdade) com a morte de crianças.

"She was the youngest living child" é seguido por "Her mother died first." As sentenças se unem com palavras como "child" e "mother", e também pela oposição "living" e "died". A mãe morre, mas é a mãe de Lena ("her mother"), usando o possessivo de "she" na oração anterior. Do que ela morreu, não sabemos (talvez no parto de uma das crianças que não sobreviveu?). Mas a qualidade de filha é alterada pela morte da mãe. Lena agora deve tomar a função de mãe. "She said 'take care of paw.' Lena did so".

O pai morre em seguida e dá outra ordem. 0 imperativo aqui aparece como present simple (uso semelhante ao presente do indicativo). "You go to Doane's Mill with McKinley. You get ready to go, be ready when he comes." Esse tempo verbal é usado para descrever rotinas e hábitos. Não há dúvidas, no entanto, que o pai está dando ordens para a jovem Lena. Com isso, podemos fazer diversas outras afirmações que não estão explícitas no texto. A primeira, as ordem recebidas e o cumprimento delas são rotinas para a nossa Lena, da qual existem outras com experiências e apuros semelhantes. Também, a morte é esperada para pessoas nessa situação e o que ocorre com as garotas órfãs é que elas devem morar

6 Uso o termo aqui também de modo irônico.

7 Não é isso o Modernismo em seus melhores dias? 
com parentes mais velhos e exercer funções de servos. $\mathrm{O}$ futuro expresso por meio do present simple representa um futuro habitual, que ocorre em horários já decididos.

O irmão mais velho já chega sem ser mais irmão. É agora guardião e patrão. Ao chegar, eles enterram o pai e voltam para a Doane's Mill, pois a carroça é emprestada e deve ser retornada ao cair da noite.

A movimentação até então aparece como obrigação e sem possibilidades de mudança. Lena deve ir para Doane's Mill porque os pais morreram e ela deve agora trabalhar para o irmão. Ele tem que buscar ela e seu tempo e trajeto são limitados, pois ele não é dono de seu meio de transporte. Os limites de movimentação fazem alusão novamente a classe social das pessoas. 0 caminhar descalço e a carroça emprestada mostram pessoas de classe baixa.

Com esse breve arranjo do passado de Lena, somos apresentados ao apuro do presente de Lena: ela está grávida e o pai da criança fugiu. Somos apresentados a isso como seremos a tudo que envolve Lena, isto é, por terceiros. Seja o narrador ou outros personagens, a voz de Lena ou opiniões sobre sua situação ganha palavras apenas no discurso dos outros. Até mesmo o discurso direto de Lena chega até nós graças à prosa de outro alguém.

The sister-in-law told the brother. Then he remarked her changing shape, which he should have noticed some time before. He was a hard man. Softness and gentleness and youth (he was just forty) and almost everything else except a kind of stubborn and despairing fortitude and the bleak heritage of his bloodpride had been sweated out of him. He called her whore. He accused the right man (young bachelor, or sawdust Casanovas anyway, were even fewer in number than families) but she would not admit it, though the man had departed six months ago. She just repeated stubbornly, 'He's going to send for me. He said he would send for me'; unshakable, sheeplike, having drawn upon upon that reserve of patient and steadfast fidelity upon which the Lucas Burches depend and trust, even though they do not intend to be present when the need for it arises. Two weeks later she climbed again through the window. It was a little difficult, this time. 'If it had been this hard to do before, I reckon I would not be doing it now," she thought. She could have departed by the door, by daylight. Nobody would have stopped her. Perhaps she knew that. But she chose to go by night, and through the window. She carried a palm leaf fan and a small bundle tied neatly in a bandana handkerchief. It contained among other things thirty-five cents in nickels and dimes. Her shoes were a pair of his own which her brother had given to her. They were but slightly worn, since in the summer neither of them wore shoes at all. When she felt the dust of the road beneath her feet she removed the shoes and carried them in her hand (ibid., p. 7).

E assim descobrimos a gravidez de Lena. Em um acordo horrível entre texto e leitor, já sabemos que o pai da criança enganou Lena e não vai voltar. Mesmo que ela diga "He's going to send for me", não acreditamos nisso. A própria Lena parece não concordar, pois ela repete a oração utilizando o discurso indireto: "He said he would send for me." 
Esse entendimento não dito entre leitor e texto escancaram o que aparece pelas beiradas. Isto é, que a maternidade é fardo para a mulher, um do qual o homem pode não participar e que a culpa da gravidez é da mulher apenas. 0 irmão "called her whore".

Uma das passagens mais interessantes de todo o romance é o encontro entre Lena e Martha Armstid. O marido de Martha dá uma carona para Lena e a leva para casa para passar a noite, sentindo pena da jovem Lena. Embora a confluência entre as duas personagens não faça com que o roteiro se desenvolva, o diálogo e a breve relação são significativas de uma representatividade maior. Martha, mesmo que muito diferente de Lena em suas singularidades, pode compreender a mais nova, pois podem compartilhar de um mesmo conjunto de experiências comum ao gênero feminino.

\begin{abstract}
He takes the team out and waters and stalls and feeds them, and lets the cows in from the pasture. Then he goes to the kitchen. She is still there, the grey woman with a cold, harsh, irascible face, who bore five children in six years and raised them to man- and woman-hood. She is not idle. He does not look at her. He goes to the sink and fills a pan from the pail and turns his sleeves back. 'Her name is Burch,' he says. 'At least that's what she says the fellow's name is that she is hunting for. Lucas Burch. Somebody told her back down the road a ways that he is in Jefferson now.' He begins to wash, his back to her. 'She come all the way from Alabama, alone and afoot, she says' (ibid., p. 14).
\end{abstract}

O Sr. Armstid teme a reação de sua esposa, que anteriormente ele chama de mulher fria. Assim, ele explica a razão de Lena estar ali como se estivesse se justificando. $O$ leitor espera uma reação rude à presença de Lena ou até mesmo um conflito: "Mrs Armstid does not look around. She is busy at the table. 'She's going to quit being alone a good while before she sees Alabama again,' she says" (ibid., p. 14). Martha não se vira para falar com o marido. Isso aumenta a sensação de que ela é uma pessoa distante. Mas a próxima sentença já nos dá uma razão para a distância dela: ela está ocupada em seus afazeres domésticos. Junte isso ao fato de que ela teve cinco filhos em seis anos (informação passada quase que pelas beiradas) e começamos a formar uma outra imagem de Martha. Então ela recebe a benesse do discurso direto. Com a vantagem de sua fala, ela demonstra que compartilha de experiências comuns com Lena: "Ela vai deixar de ficar sozinha por um bom tempo antes de ver o Alabama de novo".

'Or that fellow Burch either, I reckon.' He is quite busy at the sink, with the soap and water. And he can feel her looking at him, at the back of his head, his shoulders in the shirt of sweatfaded blue. 'She says that somebody down at Samson's told her there is a fellow named Burch or something working at the planing mill in Jefferson' (ibid., p. 14).

Voltamos àquele acordo silencioso, omisso, entre narrador e leitor masculino. Agora temos um novo cumplíce, Mr. Armstid. Ele já sabe que Lucas Burch não estará esperando por Lena. Ele já sabe que é mentira. $O$ interessante é que ele não 
afirma sua certeza. "Eu acho". Existe uma ambiguidade na próxima sentença. "E ele pode sentir ela olhando para ele, para sua nuca, seus ombros na camisa de azul desbotado pelo suor." 9 Por que estaria Martha olhando para ele? Se seguirmos o que nos é passado pelo Sr. Armstid, é porque ela é uma mulher fria e ele está explicando sua ação de levar Lena para passar a noite.

Defendo outra interpretação. Já disse que Martha e Lena em suas singularidades e diferenças compartilham de experiências comuns, universais para o grupo de mulheres poor whites. Parece-me que este momento é carregado do peso de palavras não-ditas, de conhecimentos e leis não-escritas. Mr. Armstid até onde tivemos acesso no texto não é um homem ruim, e é aí que devemos parar nossa análise em relação a esse personagem.

De qualquer modo, o marido parece estar envergonhado pela situação de Lena não porque ele é responsável por ela, mas porque como homem ele sabe que o comportamento de Lucas Burch é comum. De tal modo que a distância de Martha não é por uma questão de personalidade, mas porque ela entende a situação estando do outro lado da moeda, uma mulher. Temos acesso ao casal Armstid muito rapidamente, apenas nesse momento da jornada de Lena. Ainda assim, o diálogo está pleno de palavras não-ditas. Não apenas no que se refere a Lena e Lucas Burch, mas a relação homem-mulher e, em âmbito maior, a vida no Sul dos Estados Unidos que funciona como microcosmo de nossas vidas, apesar de todas suas especificidades.

When the wagon passes the house and goes on toward the barnlot, his wife is watching it from the front door. He does not look in that direction; he does not need to look to know that she will be there10, is there. 'Yes,' he thinks with sardonic ruefulness, turning the mules into the open gate, 'I know exactly what she is going to say. I reckon I know exactly.' He halts the wagon, he does not need to look to know that his wife is now in the kitchen, not watching now; just waiting. He halts the wagon. 'You go on to the house,' he says; he has already descended and the woman is now climbing slowly down, with that inward listening deliberation. 'When you meet somebody, it will be Martha. I'll be in when I feed the stock.' He does not watch her cross the lot and go on toward the kitchen. He does not need to. Step by step with her he enters the kitchen door also and comes upon the woman who now watches the kitchen door exactly as she had watched the wagon pass from the front one. 'I reckon I know exactly what she will say,' he thinks (ibid., pp. 13-14).

Esse trecho realça a rotina da vida dos Armstid. Não poderia a rotina ser contraposta à jornada de Lena? Ou seja, o símbolo que é a movimentação de Lena do Alabama para o Mississipi, o coração do Sul dos Estados Unidos, entra em contraste com as pessoas, costumes e coisas que se mantém daquele modo por muito tempo? Ou não entra em contraste por significar contraposição. Mas ressalta o que fica no silêncio. Ilumina os problemas e hipocrisias. A peripécia de Lena é algo novo dentro do cementado. $O$ que ocorreu com ela é comum, mas se

9 "And he can feel her looking at him, at the back of his head, his shoulders in the shirt of sweatfaded blue". 
espera que ela aceite seu destino imóvel. Do contrário, ela atravessa a estrada a pé e altera a vida daqueles com quem ela entra em contato. As rotinas ganham outra dimensão com a passagem de Lena.

No último trecho citado, o marido sabe onde a esposa vai estar: "sua mulher está olhando desde a porta da frente. Ele não olha naquela direção. Ele não precisa olhar para saber que ela estará lá." ${ }^{\prime 1}$ No trecho citado, ele e o narrador afirmam saber o que a mulher está fazendo, onde ela está e o que ela fará. No entanto, o fatalismo não se concretiza por completo. Um verbo aparece duas vezes que atenua a certeza dele. Ele diz "I reckon" em duas sentenças. A primeira é "I know exactly what she is going to say. I reckon I know exactly." A segunda oração, que faz uma elipse da primeira, diminui consideravelmente a certeza da anterior. Ele repete essa ideia em pensamento quando Lena entra na casa e ele está apreensivo com a reação da esposa. "I reckon I know exactly what she will say".

No trecho citado da p. 14, temos a voz do narrador que diz "a mulher grisalha com um rosto frio, duro, irascível que pariu cinco crianças em seis anos e os criou para idade adulta." ${ }^{\text {2 }} \mathrm{O}$ itálico é meu. Muitas coisas existem aqui. Comecemos pela parte que não dá para ser traduzida, como é a regra em Faulkner. 0 narrador diz que Martha criou cinco crianças para "man- and woman-hood". Manhood é um substantivo abstrato do período de vida quando alguém já é um homem adulto, e faz referência a todas as responsabilidades e os julgamentos de valor de um homem. Em nosso português, dizemos simplesmente "homem" acompanhado de um verbo, como "virar homem", "ser homem", etc. O narrador aqui faz questão de ironizar o termo e chamar a atenção, interrompendo o substantivo com um hífen seguido da conjunção "and" para adicionar "womanhood", o feminino do primeiro termo. Poderíamos pensar em "os criou homens e mulheres", mas perderíamos a parte carregada de ironia e o ritmo imposto na locução e em seu significado que ocorre devido a interrupção. É como se ao dizer manhood e womanhood os termos estivessem carregados dos significados que o romance até agora deram às vivências masculinas e femininas. Martha pariu esses filhos e filhas, e provavelmente essas filhas conhecem a rotina de Marthas e Lenas.

A sentença completa é "Ela ainda está lá, a mulher grisalha com o rosto frio, duro e irascível que pariu cinco crianças em seis anos e os criou para man- and woman-hood". A parte em negrito é uma oração subordinada adjetiva restritiva, ela restringe quem Martha é. Por que tem ela o rosto assim? As experiências como mulher, mãe e habitante do Sul com certeza a restringem por igual. Se lembrarmos das certezas do marido... Como é restringida essa Martha?! 
"'And she expects to find him there. Waiting. With the house all furnished and all"' (ibid., p. 15) Agora Martha restringe Lena. Ela parte das experiências comuns e assume quem Lena é e almeja ser.

He cannot tell from her voice if she is watching him or not now. He towels himself with a split floursack. 'Maybe she will. If it's running away from her he's after, I reckon he's going to find out he made a bad mistake when he stopped before he put the Mississippi River between them.' And now he knows that she is watching him: the grey woman not plump and not thin, manhard, in a serviceable grey garment worn savage and brusque, her hands on her hips, her face like those of generals who have been defeated in battle.

'You men,' she says.

'What do you want to do about it? Turn her out? Let her sleep in the barn maybe?'

'You men,' she says. 'You durn men' (ibid., p. 15).

Malditos homens. Com essa afirmação, Martha volta ao lado de Lena, o qual aparentemente ela nunca deixou. $O$ que ela diz sobre as expectativas de Lena podem ser sobre suas próprias expectativas anteriores. As palavras do marido é o que a levam a exasperação. "O que quer fazer? Mandá-la embora? Deixá-la dormir no celeiro talvez?” Malditos homens.

Em seguida as duas se encontram e conversam. Martha recusa ajuda nas tarefas domésticas, alegando que o tempo que ela precisava de ajuda com isso já passou. Lena conta a sua estória, que Martha escuta sem acreditar e Lena conta como se ela também não o fizesse. Enquanto o faz, Lena mantém suas mãos nos joelhos e os olhos no chão. Martha parece perder a paciência:

Mrs Armstid watches the lowered face. Her hands are on her hips and she watches the younger woman with an expression of cold and impersonal contempt. 'And you believe that he will be there when you get there. Granted that he ever was there at all. That he will hear you are in the same town with him, and still be there when the sun sets.'

Lena's lowered face is grave, quiet. Her hand has ceased now. It lies quite still on her lap, as if it had died there. Her voice is quiet, tranquil, stubborn. 'I reckon a family ought to all be together when a chap comes. Specially the first one. I reckon the Lord will see to that' (ibid., p. 18)

Lena oferece uma prece para que deus resolva seu problema: que seu filho nasça com a mãe e o pai juntos. $O$ curioso é que ela tomou esse destino desejado em suas mãos. Mesmo que aparentando falta de paciência, Martha decide ajudar o destino e aqui toma o papel de algo divino, ou melhor, de uma bruxa:

'And I reckon He will have to,' Mrs Armstid says, savagely, harshly. Armstid is in bed, his head propped up a little, watching her across the footboard as, still dressed, she stoops into the light of the lamp upon the dresser, hunting violently in a drawer. She produces a metal box and unlocks it with a key suspended about her neck and takes out a cloth sack which she opens and produces a small china effigy of a rooster with a slot in its back. It jingles with coins as she moves it and upends it and shakes it violently above the top of the dresser, shaking from the 
slot coins in a meagre dribbling. Armstid in the bed watches her.

'What are you fixing to do with your eggmoney this time of night?' he says.

'I reckon it's mine to do with what I like.' She stoops into the lamp, her face harsh, bitter. 'God knows it was me sweated over them and nursed them. You never lifted no hand.'

'Sho,' he says. 'I reckon it ain't any human in this country is going to dispute them hens with you, lessen it's the possums and the snakes. That rooster bank, neither,' he says. Because, stooping suddenly, she jerks off one shoe and strikes the china bank a single shattering blow. From the bed, reclining, Armstid watches her gather the remaining coins from among the china fragments and drop them with the others into the sack and knot it and reknot it three or four times with savage finality.

'You give that to her', she says. 'And come sunup you hitch up the team and take her away from here. Take her all the way to Jefferson, if you want.'

'I reckon she can get a ride in from Varner's store,' he says (ibid., pp. 18-19).

Como uma bruxa, Martha pega um simulacro de galo que continha um dinheiro que até então não tinha propósito. Quando o marido pergunta o que ela vai fazer com o dinheiro, ela o avisa que o dinheiro é dela, dinheiro que ela fez com as galinhas que ela cuida e que ele nunca levantou um dedo para ajudá-la. Incorporando as bruxas de Macbeth, Martha retorna a um período anterior ao capitalismo (o acúmulo do capital como o fim do dinheiro) usando o dinheiro para funcionar como ferramenta de Lena. Ela ordena que o marido dê o dinheiro para a jovem mulher.

Quando Lena acorda, Martha não está na casa. Mas como vimos anteriormente, aquela mulher de rosto frio, duro e irascível que pariu cinco filhos em seis anos e os transformou em homens e mulheres? Ela ainda está lá. Está com Lena e com a criança que nascerá.

Há semelhanças nas obras. Defendo que elas fazem parte de um projeto de prosa nas quais as obras fazem parte de um mosaico que, cada uma a sua maneira, tentam representar o ethos de uma nação que se encontrava entre o momento de tornar-se a maior potência mundial e o momento de sociedade escravocrata. Mas quais diferenças podemos citar que são representativas de cada obra?

A começar por $O$ Som e a Fúria, temos a interessante escolha de diferente narradores. Apenas o primeiro capítulo, narrado por Benjamin, faz uso do fluxo de consciência. Mas é necessário para o desenrolar do romance a narração em primeira pessoa e em fluxo de consciência através da vista de Benjamin? Podemos responder essa pergunta com a constatação de que se é o único capítulo assim, deve existir um motivo para essa escolha. Moretti (1996) também chama atenção para o fato de que Faulkner abandona a técnica do fluxo de consciência após o primeiro capítulo. Em outras palavras, a técnica não pôde dar conta do objeto da narrativa. Foi preciso outros narradores para poder iluminar o que nos foi apresentado por Benjamin.

Corremos o risco de entrar em uma discussão entre a galinha e o ovo. Teria o romance começado como uma experimentação técnica que extrapolou as 
possibilidades da técnica? Não me parece. Afinal, sem o capítulo narrado da maneira que temos a experiência de leitura seria completamente distinta. Ao mesmo tempo que o narrador tem limitações óbvias, ele também não possui as limitações dos outros. Com exceção do capítulo em terceira pessoa no final do romance, os outros capítulos são narrados de forma subjetiva. Quando colocados juntos, o total é maior que a soma das partes.

Nos basta agora dizer que a subjetividade de Benjamin é nula, pois ele não tem identidade. Seu capítulo é todo sobre os outros: sua irmã, os servos, sua família, etc. $O$ fluxo de consciência aqui não é as possibilidades tomando conta da narrativa de modo arbitrário. $O$ fluxo de consciência aqui leva o leitor de um momento específico (a chegada de um grupo de artistas) a outros momentos no passado que tem importância vital dentro da narrativa da decadência da família Compson.

No entanto, quando nos aprofundamos em O Som e a Fúria e estudamos com atenção as diferentes narrações da obra e o que ficou conhecido como "fluxo de consciência”, começamos a estranhar que o capítulo de Benjamin seja descrito por esse nome. Dorrit Cohn escreve sobre a técnica:

The two demands, most frequently made on the stream-of-consciousness novel are (1) that it render the consciousness directly, without the presence of a narrator; and (2) that it render not the speech, but the 'prespeech' level of consciousness. Consider for a moment what a novel would be like that followed both those criteria simultaneously: it would have to transcribe on the printed page, without the intervention of a narrator, the nonverbal content of the mind (Cohn, 1966, p. 18).

Obviamente, como Cohn ironiza nessa passagem, nenhum texto teria condições de satisfazer essas demandas. De qualquer modo, seria possível encaixar a narração de Benjamin nessa definição? O primeiro ponto fala de representar a consciência diretamente. Não temos isso no capítulo de Benjamin. Escrevi acima que a subjetividade de Benjamin é nula. O que temos em sua narração são acontecimentos que ele olha sem que dê nenhum julgamento de valor, ou sem que sua consciência possa refleti-los. Ou talvez, a falta de julgamento, a transcrição mais banal possível seja o exato reflexo que a consciência de Benjamin possa passar ao leitor. Cohn ressalta "sem a presença do narrador". Não seria a narração de Benjamin algo parecido com o oposto do primeiro ponto? Não poderíamos afirmar que Benjamin é o narrador em sua forma mais brutal, sem fazer conexões entre os atos? A escolha de Benjamin como narrador é algo que é extremamente importante.

Muito se fala do quesito experimental da obra de Faulkner, como é o caso de muitos autores sob o termo "modernismo", e 0 Som e a Fúria é uma obra que é sempre citada nesse sentido. Como dito acima, e também por Moretti (1996), a obra esgota os limites da técnica "fluxo de consciência" e os outros capítulos mudam a perspectiva e o estilo narrativo. Se, como defendo aqui, a narrativa de Benjamin é necessária para o desenrolar do capítulo e o acesso do leitor aos personagens naqueles momentos, a ideia da técnica como mera experimentação não teria bons fundamentos. 
No momento, limito-me a sugerir uma discussão que insira Faulkner no debate sobre a narrativa modernista, ou melhor, no grande debate que começa com Flaubert e o fio que esse tece até Proust, Joyce e Woolf. ${ }^{13}$ A constante busca por um novo estilo, um novo modo de narrar seus temas, como ocorre em Faulkner deveria instigar mais a crítica.

Como já mencionado, em Luz em Agosto, Lena quase não fala dela. A narração é sobre ela e sobre sua aventura, mas que chega ao leitor através dos outros. Há mudanças de forma narrativa em Luz em Agosto, momentos em que a forma oral se sobrepõe, mudanças de foco, etc. Mas a grande diferença está em outra questão.

O que define a tensão estrutural dos romances está num conflito entre tempo e espaço. ${ }^{14}$ Também é diferente como esse conflito se desenrola e também a direção dele. Em O Som e a Fúria, temos um local que enclausura os personagens. A casa da família Compson limita o romance e delinea até mesmo as tentativas de fuga do romance. A venda do terreno pelo qual Benjamin é saudoso foi usada para levar um dos filhos da família, Quentin, para estudar em Harvard. A prestigiosa universidade representa aqui outro conflito central na literatura estadunidense: norte e sul $1^{15}$. Essa tentativa de escape do local da casa, do espaço físico, falha. Quentin não consegue fugir de Jefferson, do Sul dos Estados Unidos. Ao final de seu capítulo, Quentin comete suicídio. Não consegue se desvencilhar do local onde está confinado, não apenas fisicamente, como também está confinado no tempo, em seu pai e em sua irmã.

O confinamento continua na próxima geração, exemplificado pelo nome dado à sobrinha de Quentin, que recebe o mesmo nome.

E é essa Quentin que talvez solucione o confinamento. Vítima do outro tio, Jason, a moça Quentin escapa junto com a trupe circense que aparece na cidade. Mas essa fuga tem os limites escancarados pela presença de Luster, o rapaz que não pode nem cogitar em fugir, pois a ideia não é plausível em seu ethos. Como também não o é nas gerações anteriores, como o avô de Luster.

O enredo de Luz em Agosto é também muito violento e com limites estruturais definidos. No entanto, o trajeto de Lena, que atravessa a pé o Alabama, seu

13 De interesse maior para esse estudo, há o texto que Proust escreveu sobre o estilo de Flaubert (1920), além dos estudos de Dorrit Cohn, Narrated Monologue (1966) e Transparent Minds (1978), Ann Banfield, Unspeakable Sentences (2015) e, sem sombras de dúvida, Auerbach em Mimesis (1971).

14 Os mencionados estudos de Cohn e Banfield sobre o style indirect libre, ou narrated monologue para Cohn e reported speech and thought para Banfield são muito importantes. Ambas autoras ressaltam a questão dos tempos verbais e a questão da narrativa épica. Acredito que, embora como a própria Cohn menciona que Faulkner é uma exceção da capacidade do monólogo em primeira pessoa (1978), a questão de distância temporal e a narrativa de Faulkner sejam pontos de grande importância na obra do autor estadunidense.

15 Wasserman (1994) faz um belo trajeto sobre a criação da identidade estadunidense na literatura, passando pelas crises de identificação, e diz que Faulkner representa o momento do conflito de identidade interna nos Estados Unidos, isto é, não mais apenas entre Estados Unidos e Europa, mas dentro da própria nação. Não é esse um dos caminho dialéticos que podem iluminar o processo de formação nacional? Moretti (1996) também escreve sobre nação e o sistema-mundo em relação ao que ele chama de modern Epic. Moretti também chama a atenção para a necessidade de mudança de estilo narrativo em O Som e a Fúria. 
rubicão, é uma fuga do espaço, do tempo e da sua condição bem sucedida. Na fuga dos confinamentos de Lena, ela “liberta” outros também. E os destinos daqueles que entraram em contato com ela não são mais os mesmos. A peripécia de Lena possibilita a quebra da estagnação temporal. Talvez a existência de conjugações de tempos futuros. 


\section{Q Bibliografia}

" Auerbach, E. (1971). Mimesis: a representação da realidade na literatura ocidental. São Paulo: Perspectiva.

"Banfield, A. (2015). Unspeakable Sentences. Narration and Representation in the Language of Fiction. Boston: Routledge.

" Cohn, D. (primavera de 1966). "Narrated Monologue: Definition of a Fictional Style". Comparative Literature 18(2), 97-112.

" Cohn, D. (1978). Transparent Minds. Narrative Modes for Presenting Consciousness in Fiction. Princeton: Princeton University Press.

" Faulkner, W. Light in August. Londres: Vintage, 2005.

" Faulkner, W. (1990) The Sound and the Fury. Nueva York: Vintage.

"Moretti, F. (1996). Modern Epic: The World System from Goethe to García Márquez. Londres: Verso.

"Oklopcic, B. (2014). Faulkner and the Native Keystone. Reading (Beyond) the American South. Heidelberg: Springer, 2014.

" Proust, M. (1920). "À propos du style de Flaubert". La nouvelle revue française XIV, pp. 72-90.

" Ross, S. M. (1996). Reading Faulkner: The Sound and the Fury. Mississippi: University Press of Mississippi.

" Ruppersburg, H. (1994). Reading Faulkner: Light in August. Mississippi: University Press of Mississippi, 1994.

"Wasserman, R. R. Mautner (1994). Exotic nations. Literature and cultural identity in the United States and Brazil, 1830-1930. Nueva York: Cornell University. 